\title{
First results of MWC SAS3 electromagnetic wave experiment on board of the CHIBIS-M satellite
}

\author{
Stanislav Klimov ${ }^{(4)}$, Csaba Ferencz ${ }^{(1)}, \dagger$ László Bodnár $^{(2)}$, Péter Szegedi ${ }^{(2)}$, \\ Péter Steinbach ${ }^{(3)}$, Vladimir Gotlib ${ }^{(4)}$, Denis Novikov ${ }^{(4)}$, Serhiy Belyayev ${ }^{(5)}$, Andrey \\ Marusenkov $^{(5)}$, Orsolya Ferencz ${ }^{(1,6)}$, Valery Korepanov ${ }^{(5)}$, János Lichtenberger ${ }^{(1,6)}$ and \\ Dániel Hamar ${ }^{(1)}$ \\ (1) Eötvös Lóránd University, Budapest, Hungary; e-mail: spacerg @sas.elte.hu \\ (2) BL Electronics Ltd., Solymár, Hungary \\ (3) MTA-ELTE Res. Group for Geol., Geophys. and Space Sci., HAS, Budapest, Hungary \\ (4) Space Research Institue (IKI) of RAS, Moscow, Russia \\ (5) Lviv Centre of Institute for Spacer Research of NASU-SSAU (LC), Lviv, Ukraine \\ (6) Geodetic and Geophysical Institute, RCAES, HAS, Sopron, Hungary
}

\begin{abstract}
The main goals of the Chibis-M mission are the testing of a new micro-satellite technology, the study of new physical processes related to lightning activity and the verification of possible monitoring techniques of Space Weather phenomena. In frames of the Chibis-M mission an electromagnetic wave complex MWC is installed on board of the satellite composed of electromagnetic sensors and SAS3 measuring unit. The obtained data show that the scientific instrumentation operates properly and produces interesting information. Here we present the first results of the first year of operation of the MWC in the ELF-VLF bands in different operation modes. An important conclusion is that basing on the experience of the first year it is possible to realize an effective and reliable Space Weather monitoring system using micro-satellites and simultaneously operating ground support equipments.
\end{abstract}




\section{Introduction}

Applying new micro-satellite technologies in high altitude atmosphere research is an actual task in recent space activities [Klimov et al., 2007]. Using cheaper and specific goal oriented research satellites the increasing of the effectiveness of the search of atmospheric processes is possible and it may be expected that in the future the operation of Space Weather and high atmosphere monitoring satellite systems will be more reliable. Therefore the development of a new micro-satellite using new cheaper launch technology is an important actual task. [Klimov et al., 2009a] The Chibis-M was launched from the Baikonur launch site in late autumn of 2011 to the ISS as a piggy-back load onboard Progress transport cargo vehicle. After the finishing of the common role of the Progress space vehicle as to the delivery of cargo to the ISS and its separation from the ISS the Progress space vehicle raised its orbit altitude using remaining fuel and the Chibis-M micro-satellite was separated from it and was delivered at the circular orbit $513 \mathrm{~km}$ height and $52^{\circ}$ inclination. By this successful launch the new inexpensive launch technology applicability was confirmed.

Beside the main task - to explore new physical processes originated at high altitude atmospheric lightning discharges including formation mechanisms of gamma ray bursts, infrared and ultraviolet radiation - the investigation of the electromagnetic environment of the Earth as a part of the Space Weather research and the understanding of the Earth global changing processes as well as the search of possible precursors of seismic activity are also in the scope of "Chibis-M" mission [Klimov et al., 2009b]. The importance of the Space Weather monitoring is well known, see e.g. in [Bobrinsky, 2009], as the searching of very reliable earthquake precursors also, see e.g. in [Molchanov et al., 2006, Parrot et al., 2006, Akhoondzadeh et al., 2010, Zeren et al., 2012]. But the investigation and monitoring of the electromagnetic environment of the Earth and of the Earth-like planets (e.g. Moon, Venus, Mars and Mercury) has also great importance, because this opens the door for the comparative study of these planets, their evolutions and actual states. A good illustration of this is the comparison of the lightning or electric discharge transient activity of the Earth and the Venus. There is evidence that on the Earth lightning or more precisely Earth-like lightning activity exists. On the Venus the electric discharges also exist which activity was recorded by Venera space probes and by the Pioneer Venus space probe [Ksanfomaliti, 1979, Taylor et al., 1979]. This was confirmed by the Venus Express space probe too [Russell et al., 2007]. However, the Cassini space probe during two Venus and one Earth fly-bys also studied electromagnetic activity of both planets and did not detect signals of lightning at Venus, at least Earth-like lightning [Gurnett et al., 2001]. The probable cause of this contradiction between the data of the different Venus missions is the fact that the Cassini measured electromagnetic oscillations in the $125 \mathrm{kHz}-16 \mathrm{MHz}$ bands and the other Venus missions in the ULF-VLF bands. But in this case this fact means that the Venus electric discharge mechanism differs from the Earth-like lightning. If this is true, it means that the electric discharge activity, i.e. the electromagnetic environment of a hot planet (like Venus) differs from the electromagnetic environment of the Earth having life on its surface. Other interesting fact is that, investigating the long-time trend in some important areas of the Earth atmospheric electrical parameters [Märcz and Harrison, 2003], VLF natural signal intensity [Smith et

al., 2008], Schumann resonance intensity [Sátori et al., 2009], a significant decreasing of 
the total lightning activity was detected. Is the cause of this phenomenon the actual global warming of our planet? Actually we have no final answer to this important question what allows us to say that the satellite monitoring of the lightning and electromagnetic environment of the Earth is a very actual task. This is the reason why such a study is between the main scientific tasks of the Chibis-M mission.

\section{Short description of the Chibis-M mission}

To explore new physical processes at high altitude atmospheric lightning discharges and formation mechanisms of gamma-ray bursts, infrared and ultraviolet radiation, electromagnetic radiation in a wide range of frequencies, the measurements have to be carried out in the ionosphere, with unprecedented high time resolution (better of the order of microseconds), simultaneously in radio, optical and gamma bands. The micro-satellite "Chibis-M" (Figure 1), designed for the study of these physical processes at high-altitude atmospheric lightning discharges, has the dedicated on-board scientific equipment (SE "Groza"), including:

$>\mathrm{X}$-gamma detector (RGD) to the range of X-ray and gamma-ray $0.02-1.0 \mathrm{MeV}-$ (Institute of Nuclear Physics of Moscow State University);

D UV detector (DUF) of the spectrum of radiation from the UV (180-400 nm) to IR (650-800nm) - (Institute of Nuclear Physics, Moscow State University);

$>$ Radiofrequency analyzer (RFA) in the frequency range $26-48 \mathrm{MHz}$ - (Space Research Institute of Russian Academy of Sciences);

D Digital Camera (TsFK) with a spatial resolution of $300 \mathrm{~m}$ and the exposure time of 15 frames / sec - (Space Research Institute of Russian Academy of Sciences);

$>$ Magnetic wave complex (MWC) in the frequency range of $0.1 \mathrm{~Hz}-40 \mathrm{kHz}-$ (sensors - Lviv Centre of Institute for Space Research of NASU-SSAU; the SAS3 instrument - Space Research Group of Eötvös University and BL Electronics Ltd.);

$>$ Data acquisition unit (BND) - (Space Research Institute of Russian Academy of Sciences);

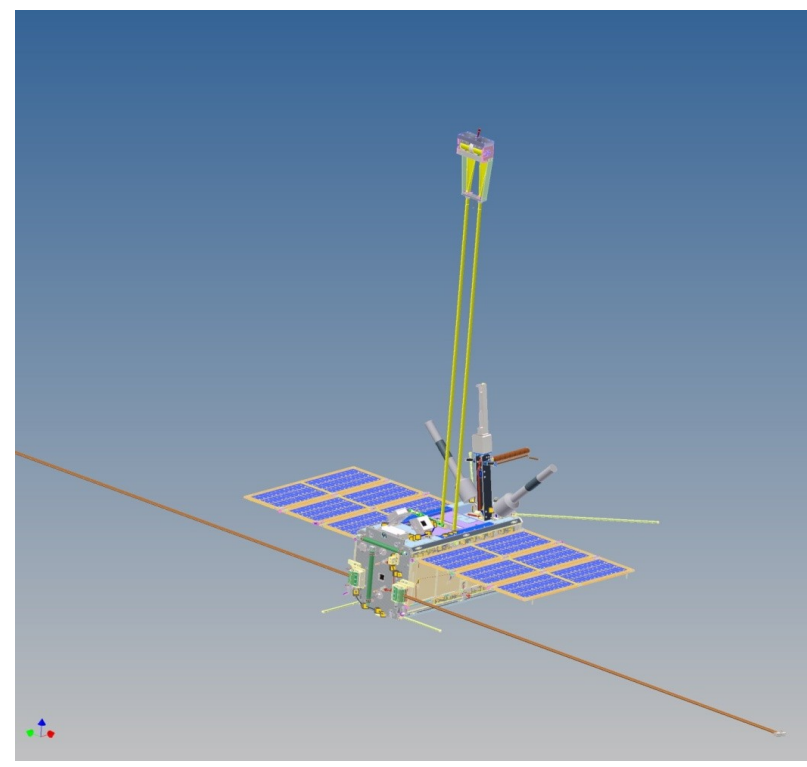


Figure 1a. The sketch of the Chibis-M micro-satellite

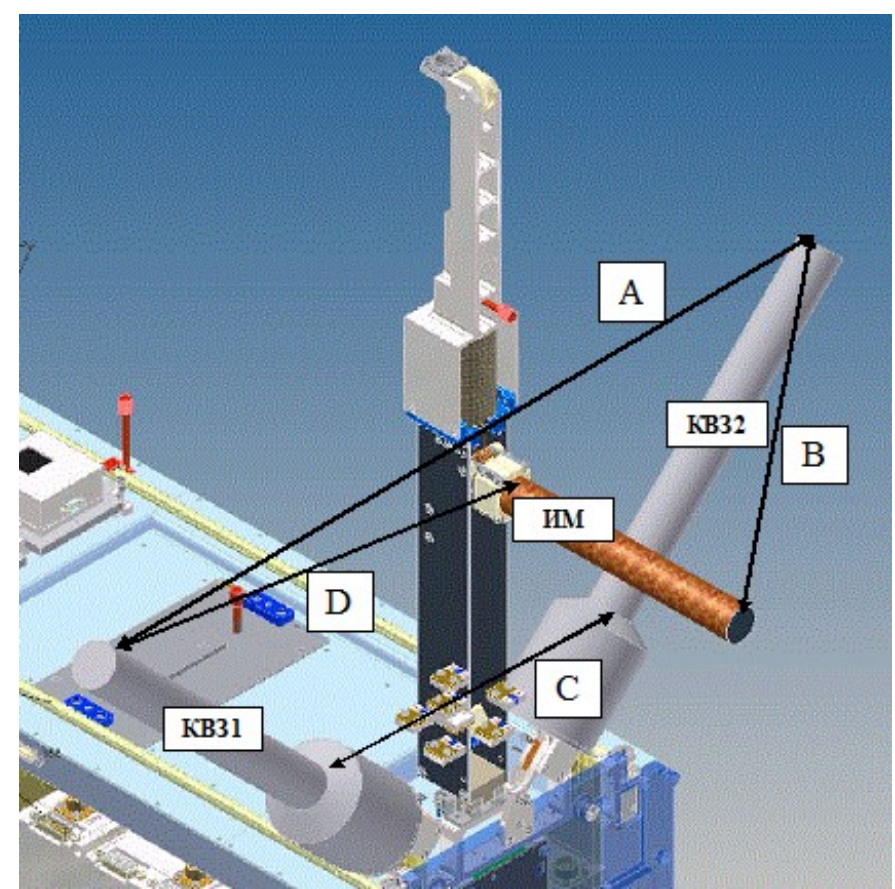

Figure 1b. Sensors of the MWC: KB31 and KB32 - combined wave probes WP (sensor length $245 \mathrm{~mm}$ ), ИМ - the induction magnetometer (sensor length $205 \mathrm{~mm}$ ).

Configuration: $A=597 \mathrm{~mm} ; B=376 \mathrm{~mm}, C=250 \mathrm{~mm}, D=299 \mathrm{~mm}$,

Each device of the SE "Groza" included in the lightning investigating group has a ringmemory (RM). The total size of this ring-memory is defined by the maximum duration of the events of a given device, which is set by PI of the experiment. Multiple events can be controlled by commands. For example these durations are: RFA-50 ms, RGD-20 ms, DUF$100 \mathrm{~ms}$. By the telecommands from the Earth other parameters may be set to capture the lightning events: the period of sampling (sampling time), the criterion of "event occurred" (EO - trigger), the size of the data "before" and "after" event. Only the events matching the EO criteria are written in RM. Events occur randomly, so those fixed in RM are connected to the EO time, and the formulation of the array of the event (title, number, etc.) is also stored. This instrumentation gives a good possibility for the lightning investigations. Inside this instrument group the MWC and its core equipment the SAS3 has other possibilities too. They will be describing below.

MWC is the main unit responsible for Space Weather and electromagnetic activity investigations. The SAS3 onboard Chibis-M is a complex and flexible electromagnetic wave measuring and data managing equipment (see Figure 2). It contains two equivalent SAS3 units A and B, by this one of them is in operation and another one in a cold backup mode. The mass of the SAS3 is $1200 \mathrm{~g}$ the power consumption together with the sensors is $<5 \mathrm{~W}$. During the operation of the SAS3 it is possible using telemetry commands to select which of A and B unit is active inside the SAS3, as well as the operation parameters of the unit like input gain setting of the amplifiers, main operation mode and parameters of the selected operation mode including the sampling rate of the recorded signals. The maximum sampling rate is $78.125 \mathrm{kHz}$ for each of 6 channels, the channels 
are sampled simultaneously and the gain of input amplifiers is possible to change from $-10 \mathrm{~dB}$ to $+26 \mathrm{~dB}$ in 4 steps.

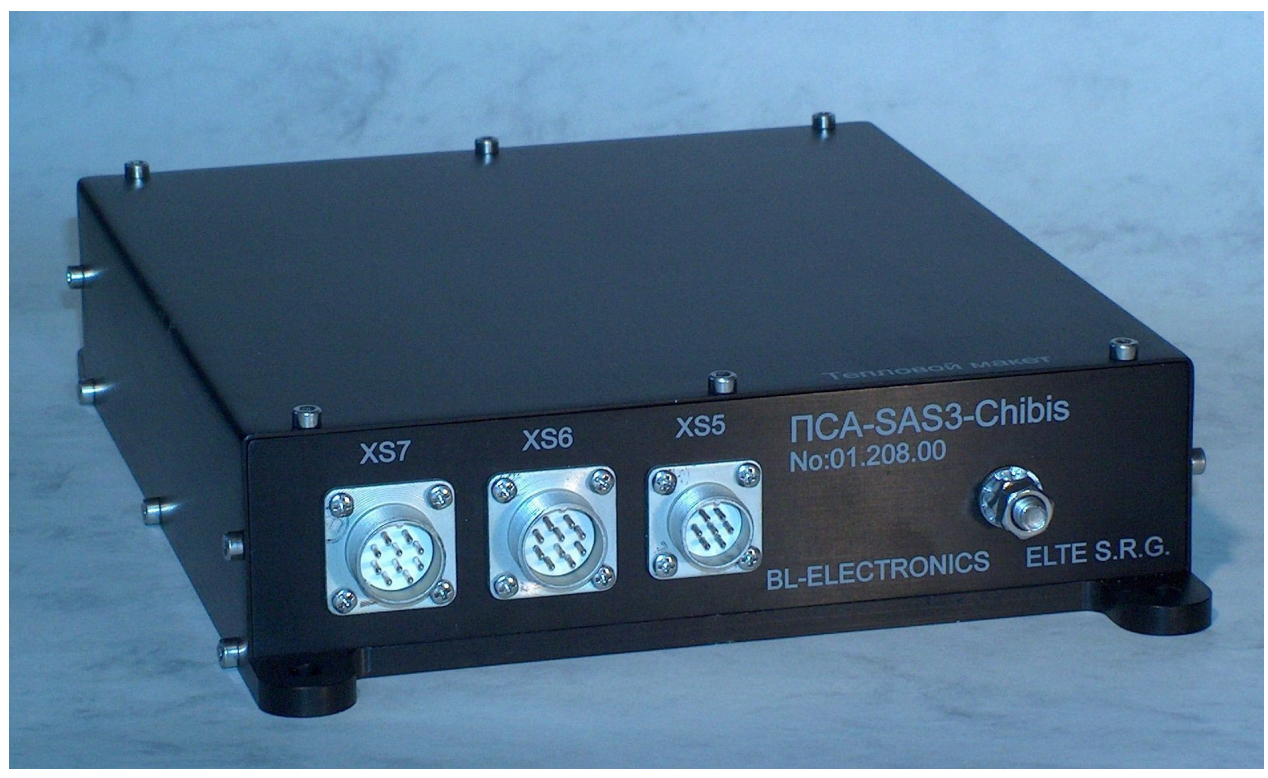

Figure 2. The SAS3 instrument for Chibis-M micro-satellite

As the SAS3 sensors two devices named "wave probe" (WP) are used each of which is a combination of three sensors in one module: split Langmuir probe, search-coil magnetometer and electric probe [Korepanov, 2003]. This instrument was successfully tested in the space environment in the Variant experiment on board of Ukrainian Sich-1M satellite launched in 2004 [Dudkin et al., 2009]. The third sensor is a search-coil magnetometer. Their operational frequency range is from $0.1 \mathrm{~Hz}$ to $40 \mathrm{kHz}$. The direction of the recorded E field is in line with the mid-points of the WP1 and WP2 sensors (KB31 and KB32) which are oblique to solar panels and satellite body (see in Fig.1b).

The SAS3 in integrated position onboard of the Chibis-M is presented in Figure 3 during the final assembly and complex tests of the microsatellite. 


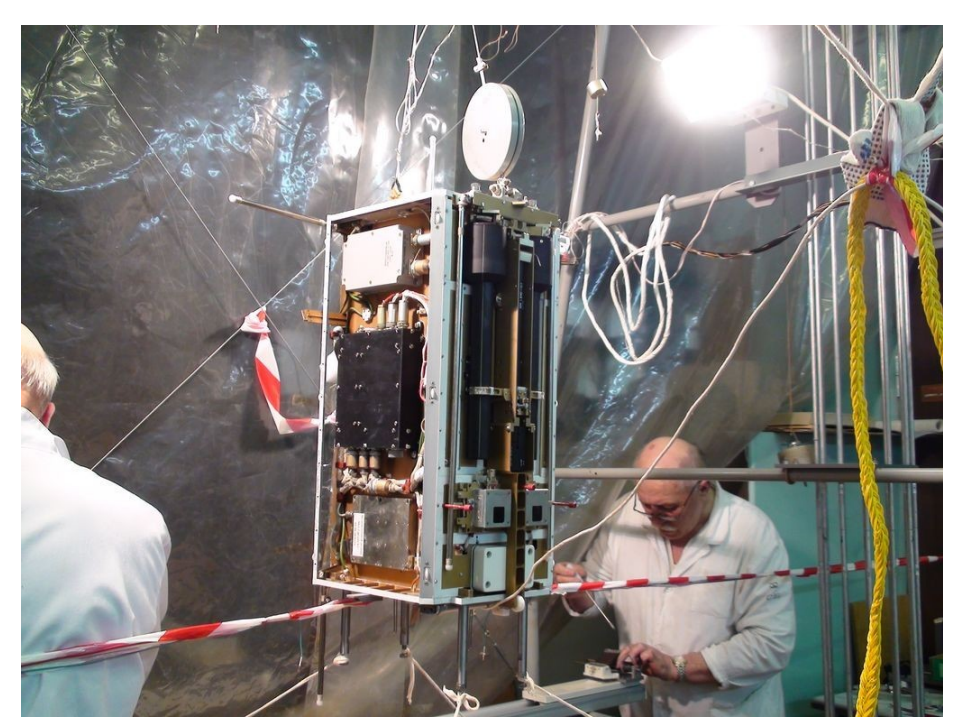

Figure3. The SAS3 on board of the Chibis-M microsatellite during the integration works.

The SAS3 unit has 6 VLF channels: three magnetic sensors in the range $0.1 \mathrm{~Hz}$ to $40 \mathrm{kHz}$ band, two split Langmuir probes in the range $0.1 \mathrm{~Hz}$ to $40 \mathrm{kHz}$, and one electric field channel in the range DC to $40 \mathrm{kHz}$. Beside these channels the SAS3 has four ULF channels able to receive information within DC to $167 \mathrm{~Hz}$ range. The noise limits data of the six ULF-VLF channels are given in Table 1.

Table 1. Noise limit data of the VLF channels

\begin{tabular}{|c|c|c|}
\hline Channel & BW & Noise \\
\hline $\mathrm{B}_{\mathrm{x}}, \mathrm{B}_{\mathrm{y}}$ & $0.1 \mathrm{~Hz}-40 \mathrm{kHz}$ & $0.084 \mathrm{pT} / \mathrm{Hz}^{1 / 2}$ \\
\hline $\mathrm{B}_{\mathrm{z}}$ & $0.1 \mathrm{~Hz}-40 \mathrm{kHz}$ & $0.047 \mathrm{pT} / \mathrm{Hz}^{1 / 2}$ \\
\hline $\mathrm{I}_{1}, \mathrm{I}_{2}$ & $0.1 \mathrm{~Hz}-40 \mathrm{kHz}$ & $120 \mathrm{pA} / \mathrm{cm}^{2} * \mathrm{~Hz}^{1 / 2}$ \\
\hline $\mathrm{U}\left(\right.$ E field component is orthogonal to $\left.\mathrm{B}_{\mathrm{z}}\right)$ & $\mathrm{DC}-40 \mathrm{kHz}$ & $0.8(\mu \mathrm{m} / \mathrm{m}) / \mathrm{Hz}^{1 / 2}$ \\
\hline
\end{tabular}

The transfer function of search coils is linear in $1 \mathrm{~Hz}$ to $1 \mathrm{kHz}$ band, flat within $3 \mathrm{~dB}$ range in $1 \mathrm{kHz}$ to $20 \mathrm{kHz}$ band and linear with slow decreasing in 20 to $40 \mathrm{kHz}$ band; in the case of the electric channel flat in the $1 \mathrm{~Hz}$ to $\leq 40 \mathrm{kHz}$ band. The sensitivity limits as a function of the frequency are on $2 \mathrm{pT} / \sqrt{\mathrm{Hz}}$ at $10 \mathrm{~Hz}, 0.2 \mathrm{pT} / \sqrt{\mathrm{Hz}}$ at $100 \mathrm{~Hz}, 0.03$ $p T / \sqrt{\mathrm{Hz}}$ at $1 \mathrm{kHz}$ and $0.02 \leq 0.03 \mathrm{pT} / \sqrt{\mathrm{Hz}}$ at $10 \mathrm{kHz}$ for search coils and $40 \mathrm{nV} / \sqrt{\mathrm{Hz}}$ at $10 \mathrm{~Hz}, 20 \mathrm{nV} / \sqrt{\mathrm{Hz}}$ at $10 \mathrm{kHz}$ for electric sensor (two probes). Unfortunately, as the experimental data showed, plasma current density channels were not operational by unknown reason.

The SAS3 can works simultaneously in three operation modes:

a) Monitoring mode, in which the SAS3 records and stores FFT spectral lines in two possible sub-modes. The selection between the sub-modes is commandcontrolled. The two sub-modes are:

(1) Monitoring of the electromagnetic spectra of selected channels without averaging. This mode produces one FFT line in every $16 \mathrm{~s}$ which results a FFT map of the general electromagnetic activity along the orbit. 
(2) Monitoring of the electromagnetic spectra of selected channels with averaging. The averaging time can be set by commands from $1 \mathrm{~s}$ to $1 \mathrm{~min}$.

b) Waveform (burst) recording mode, in which the incoming signal waveform is recorded by the SAS3 in the complete ELF-VLF band continuously or during the given time-sequence predefined by commands with two sub-modes:

(1) Periodical, time controlled data collection. In this mode the SAS3 detects and stores the incoming data of selected channels with predefined sampling rate (normal "burst" mode) without triggering event detection, using a command controlled (predefined) registration time schedule list.

(2) Real-time waveform downloads. One selected channel can be downloaded real-time over the receiving station through the $1 \mathrm{Mbit} / \mathrm{s}$ S-band downlink of the Chibis-M.

c) Event detection mode, in which the SAS3 counts the number of the incoming events (predefined transients, e.g. whistlers or longer events, fractional hop whistlers or short events, etc.) in every 1 minute long time-windows along the orbit. If the system detect a real event, then the system read the recorded signal values stored in a circular buffer memory e.g. $0.5 \mathrm{~s}$ before and 1 or $2 \mathrm{~s}$ after the inner trigger signal. However, the counting of the events, i.e. the number of the inner trigger signals is also possible without the storing of the wave-patterns of the detected events. This mode produces a transient activity picture (map) in the ionosphere along the orbit.

If we apply the "event counting" mode (with 1 min long counting time window) and simultaneously the "monitoring (2)" mode with 1 min long averaging time, than the two recorded data set (transient activity and averaged general VLF activity) is completely compatible.

The SAS3 can operate with inner triggering, i.e. to record the complete waveform of an incoming event only without a continuous burst recording. Therefore it is possible to collect detailed waveform samples during the "event detection" and control the operation of the event detector software.

Beside these modes the SAS3 can receive triggering signals from other instruments. In this case the SAS3 records the incoming VLF wave-patterns in a time sequence selected by the outer triggering signal simultaneously with the other on board instruments.

The recorded data are stored in the SAS3 inner memory and they may be transferred to the central telemetry of the satellite or directly to the S-band down-link transmitter. However, in this first technological test mission the down-link channel capacity creates a limitation of the recorded data mass of the wave complex, what is expected to eliminate for the future Space Weather and electromagnetic environment monitoring satellite services.

\section{Results in the monitoring mode}

The first results are informative about the geomagnetic activity, i.e. the Space Weather events. Let we see the $K p$ index data of the geomagnetic activity in the end of March - beginning of April and in the middle of October 2012 periods (Fig. 4). (We used in this investigation the Potsdam and Kyoto $K p$ index data base.) Red arrows in the Fig. 4 are in that days where the examples presented in Figs. 5, 6 and 7 were recorded. Each 
record on these figures is 6 hours long in monitoring mode of SAS3. It is clear that in the selected days the geomagnetic activity was quiet, active or stormy. The Chibis-M orbit is successful because in the highest latitudinal positions the satellite reaches the polar (auroral) regions and the orbit height is a little bit higher then the height of the electron density maximum of the ionosphere F2 layer.

In the monitoring pictures (Figs. 5, 6 and 7) from top to down the spectral data of the recorded electromagnetic field strengths are presented, below these measured data the sub-satellite line of the Chibis-M and bottom the L-values are presented. The horizontal axis is the time (UT+3 hours, Moscow-time). $31^{\text {st }}$ March 2012 was a geomagnetically quiet day (Fig. 5), in $1^{\text {st }}$ April 2012 the geomagnetic activity was higher (Fig. 6) then $31^{\text {st }}$ March, i.e. it is "normal", "typical" activity, and in $13^{\text {th }}$ October 2012 was a geomagnetic storm (Fig. 7), as it is evident in Fig. 4. In details the panels in the Figs. 5, 6 and 7 are the following: The top four panels from top to down contain the FFT map formed by the FFT lines of the $\mathrm{E}, \mathrm{B}_{\mathrm{x}}, \mathrm{B}_{\mathrm{y}}$ and $\mathrm{B}_{\mathrm{z}}$ input channels recorded in every $16 \mathrm{~s}$ without any averaging, i.e. SAS3 operated in "monitoring mode (1)". (The vertical lines, i.e. interferences in $B_{x}$ and $\mathrm{B}_{\mathrm{y}}$ data are onboard EMC noise effects, produced by the active phases of the satellite orientation system. These two search coil sensors are closer to the satellite body and in different position than the third one, see in the Fig. 1b.) In the fifth panel the white dashed line is the sub-satellite line of the Chibis-M satellite on the map of the Earth surface and the sixth panel contains the simultaneous L-values of the satellite position (light green line).
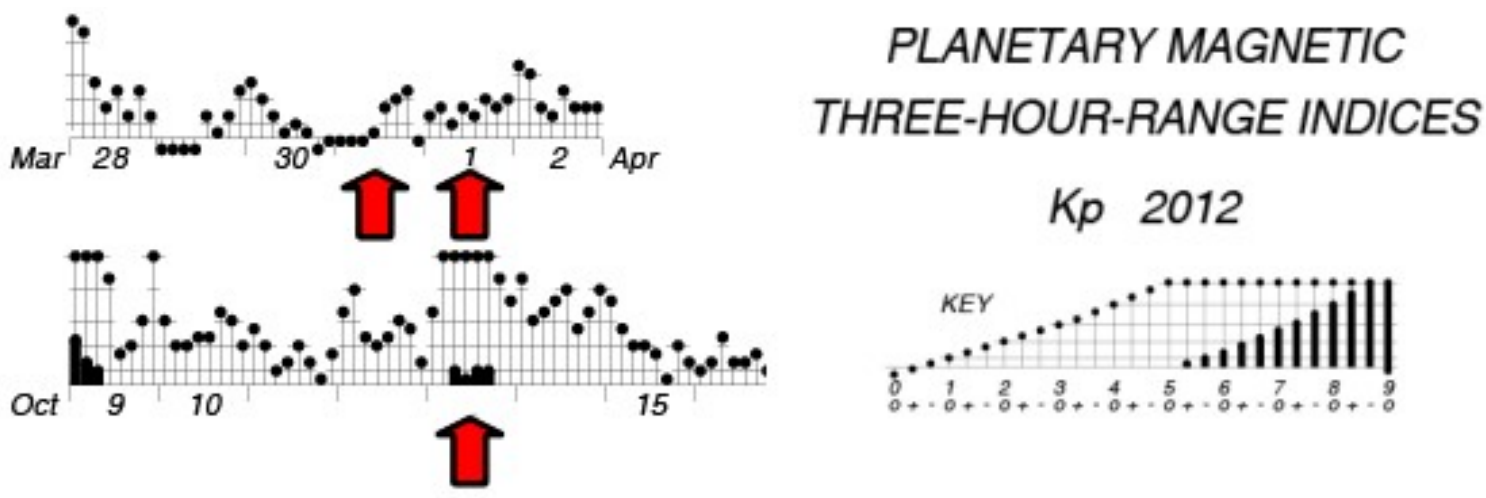

Figure 4. Geomagnetic activity, the Kp index curves from 28.032012 to 02.04 .2012 (top) and from 09.10.2012 to 15.10.2012 (bottom). (See more in the text.)

In the "quiet day" $31^{\text {st }}$ March the $K p$ index values are very small, near to 0 (Fig. 4), the Dst values were in the +8 to $+12 \mathrm{nT}$ band and the FFT spectrum along the orbit (Fig. 5) is clean. (We used in this investigation the "Dst Kyoto" data base.) Only above the Pacific Ocean is a little bit higher, but low ELF-VLF activity.

In the "typical day" $1^{\text {st }}$ April the $K p$ index values are small (from 1 to 2), but higher than in $31^{\text {st }}$ March (Fig. 4), the Dst values changed from +12 to $-17 \mathrm{nT}$ and the FFT spectrum (Fig. 6) has higher noise level mainly below $20 \mathrm{kHz}$ and more high activity in the polar, i.e. in the South Polar Region. However, this activity in most cases typically remains below $20 \mathrm{kHz}$. 
However, during the geomagnetic storm in $13^{\text {th }}$ October the $K p$ index was really high around 6 (Fig. 4), the Dst values started at $-20 \mathrm{nT}$ increasing to $-79 \mathrm{nT}$ and decreasing with some fluctuation to $-45 \mathrm{nT}$; the VLF activity level in the FFT spectrum (Figs. 7a and 7b) is really high typically in and around the Sub-Auroral Regions in a good correlation with the actual $D s t$ values and this intense VLF noise activity appears with high intensity in the higher than $20 \mathrm{kHz}$ band with remarkable intensity.

It seems to us that only in the case of very high geomagnetic activity (i.e. geomagnetic storm) a very high VLF activity appears in the $\geq 20 \mathrm{kHz}$ to $\leq 40 \mathrm{kHz}$ VLF band and mainly in the Sub-Auroral Regions. Further detailed discussion of the Chibis SAS3 monitoring data is under way and the Chibis-M systematically collects this type of data. 


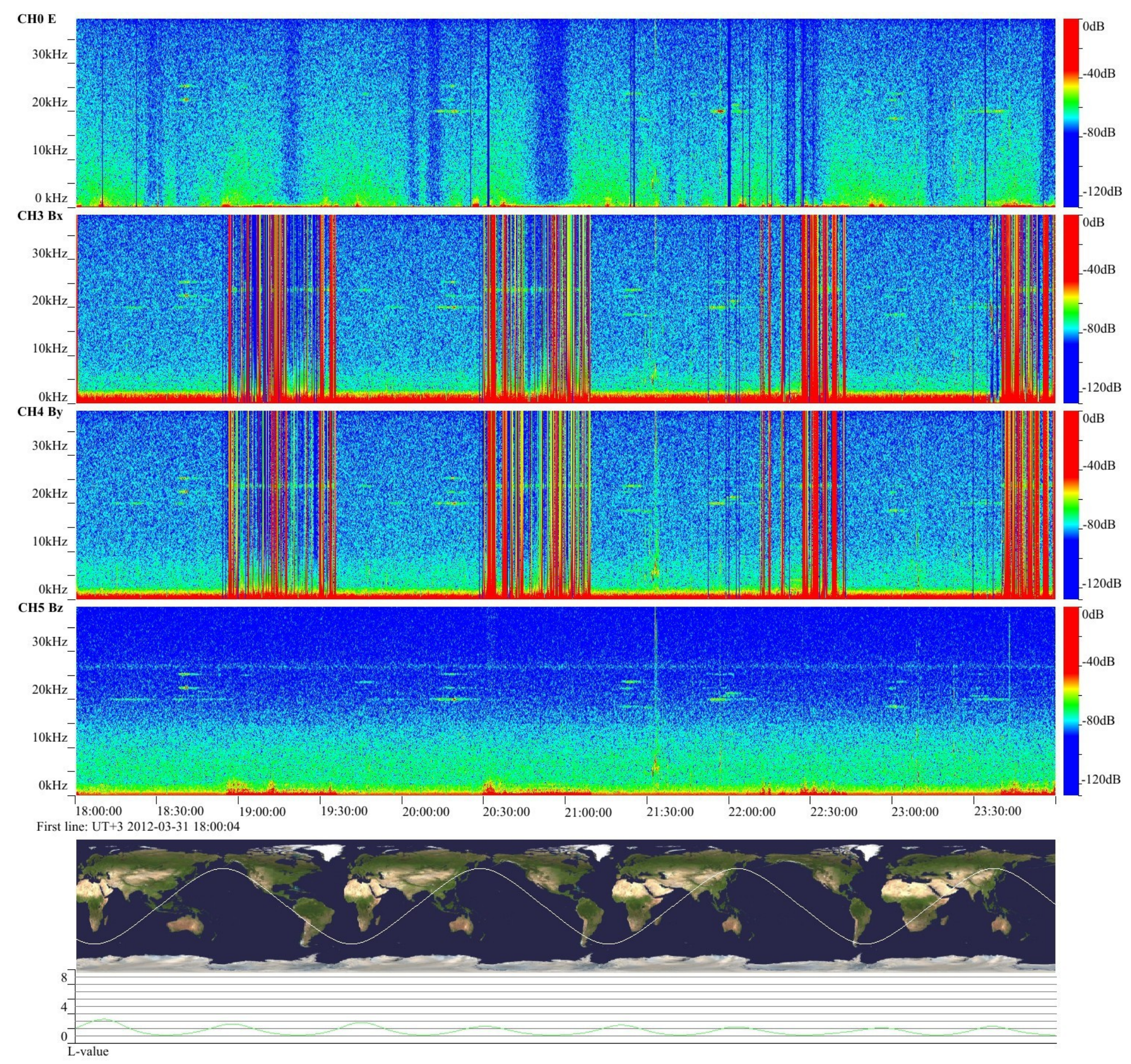

Figure 5. Monitoring mode (1) SAS3 data recorded by the Chibis-M in 31 $1^{\text {st }}$ March 2012. The beginning of the 6 hours long record is $U T+3=18.00 .00$. 


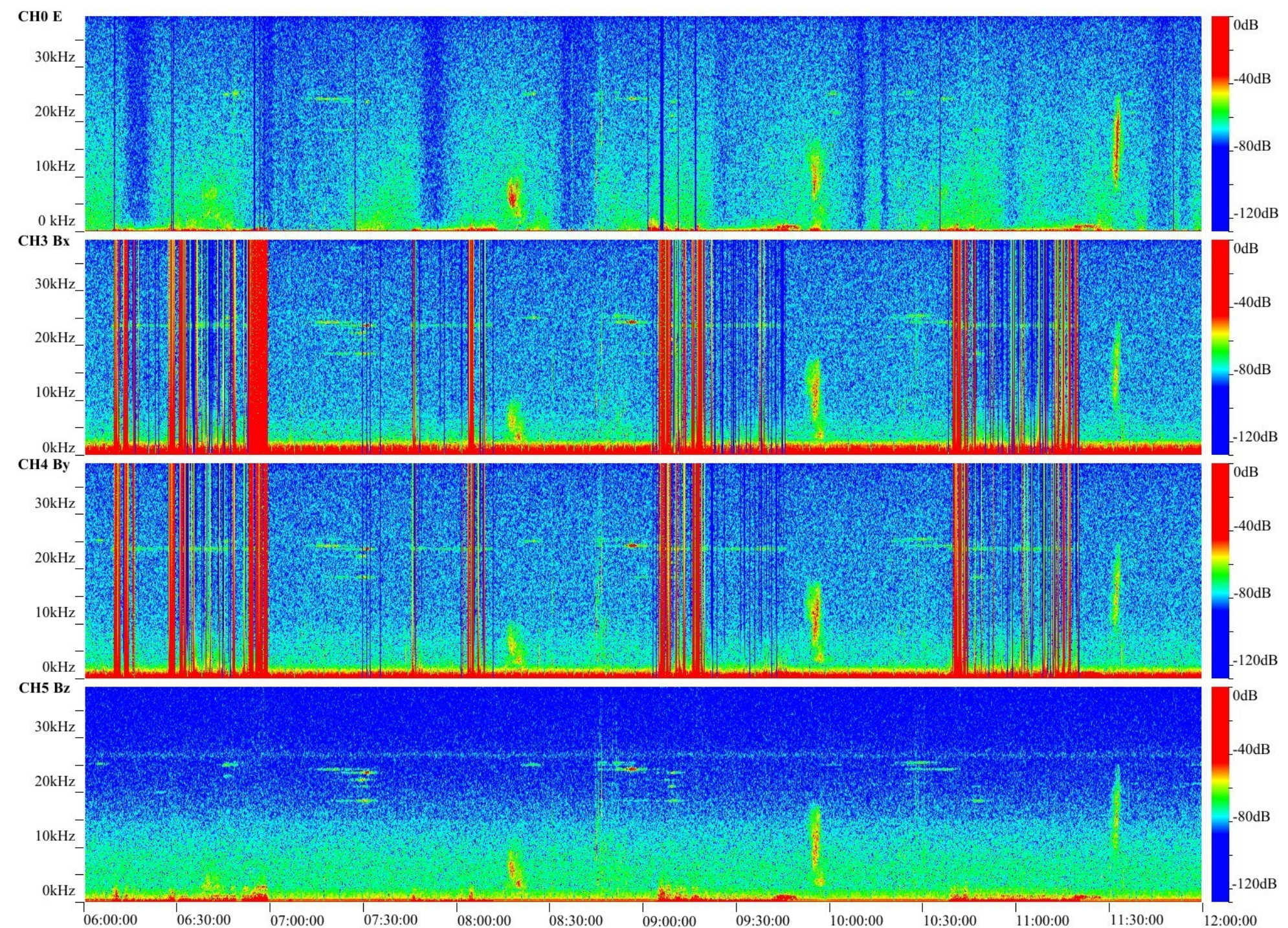

First line: UT+3 2012-04-01 06:00:11
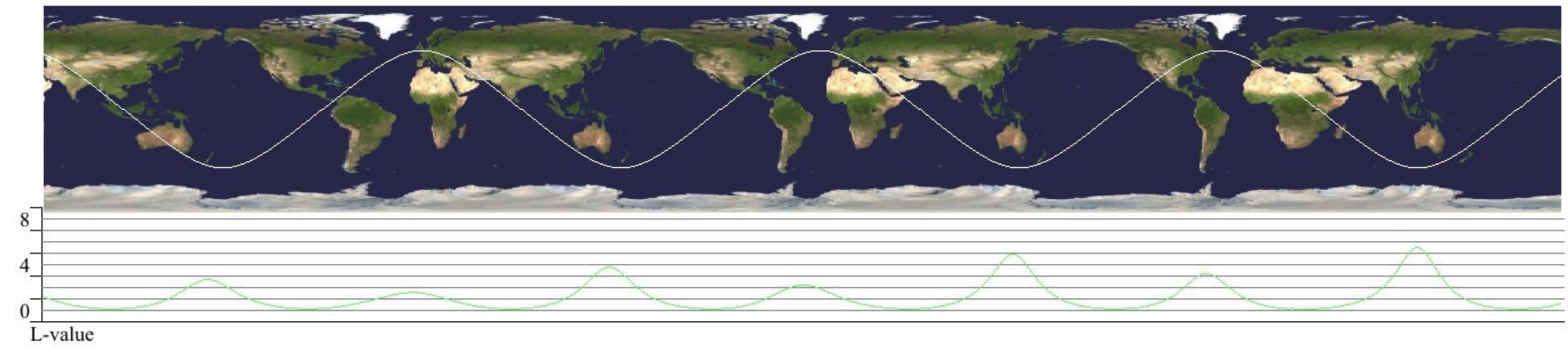

Figure 6. Monitoring mode (1) SAS3 data recorded by the Chibis-M in $1^{\text {st }}$ April 2012. The beginning of the 6 hours long record is $U T+3=06.00 .00$. 


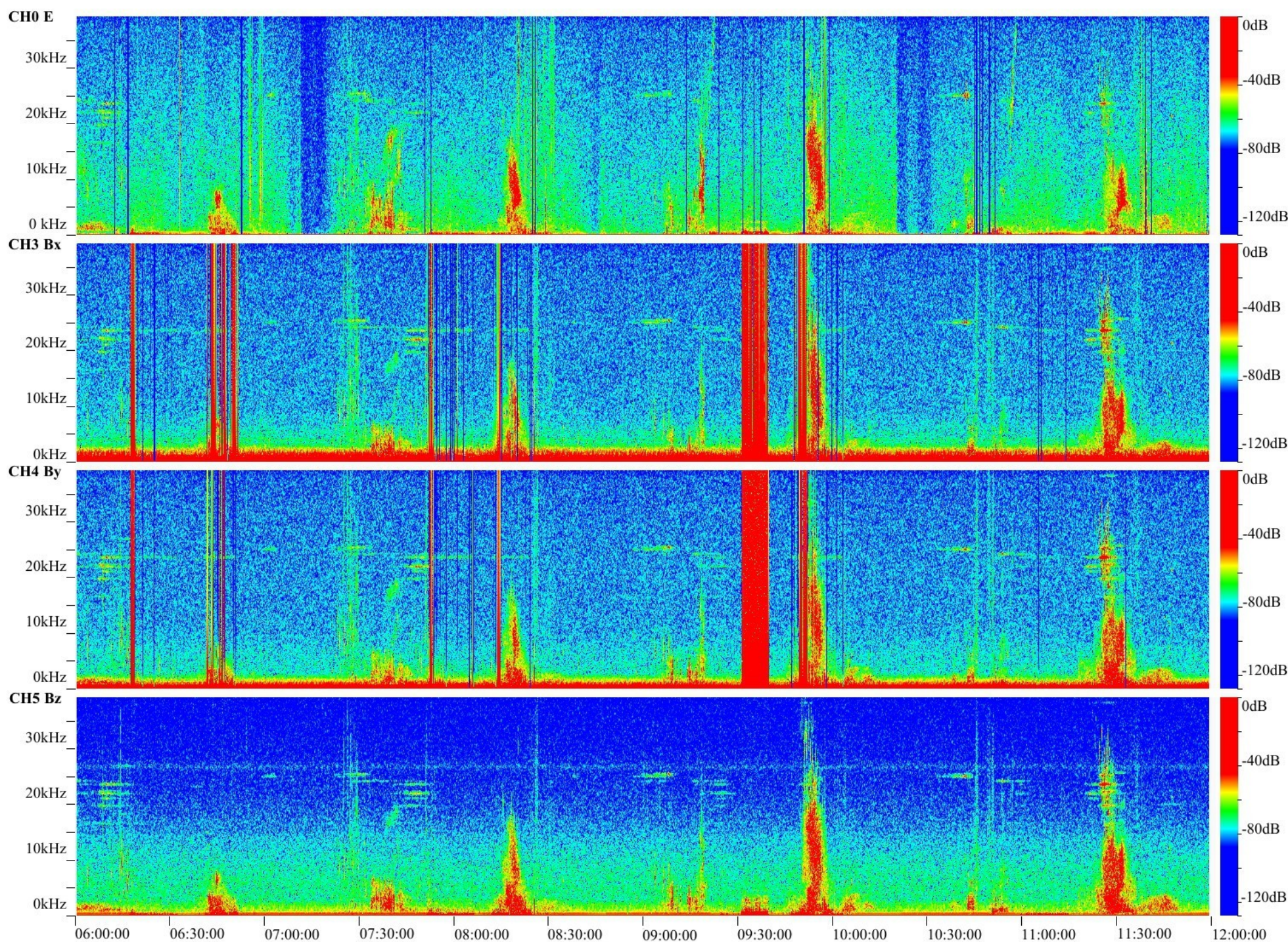

First line: UT+3 2012-10-13 06:00:14
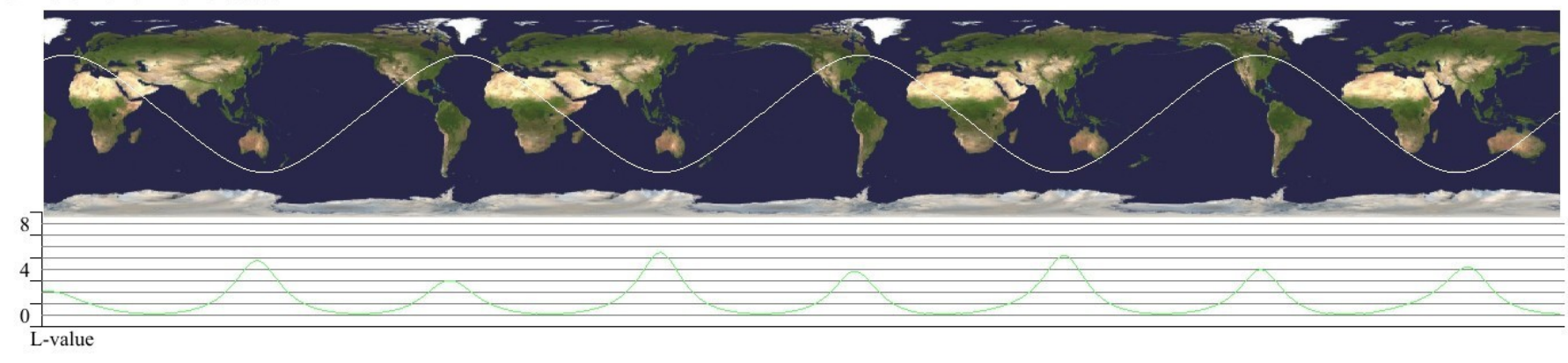

Figure 7a. Monitoring mode (1) SAS3 data recorded by the Chibis-M in $13^{\text {th }}$ October 2012. This record contains the beginning and the first part of the geomagnetic storm. The beginning of the 6 hours long record is $U T+3=06.00 .00$. 


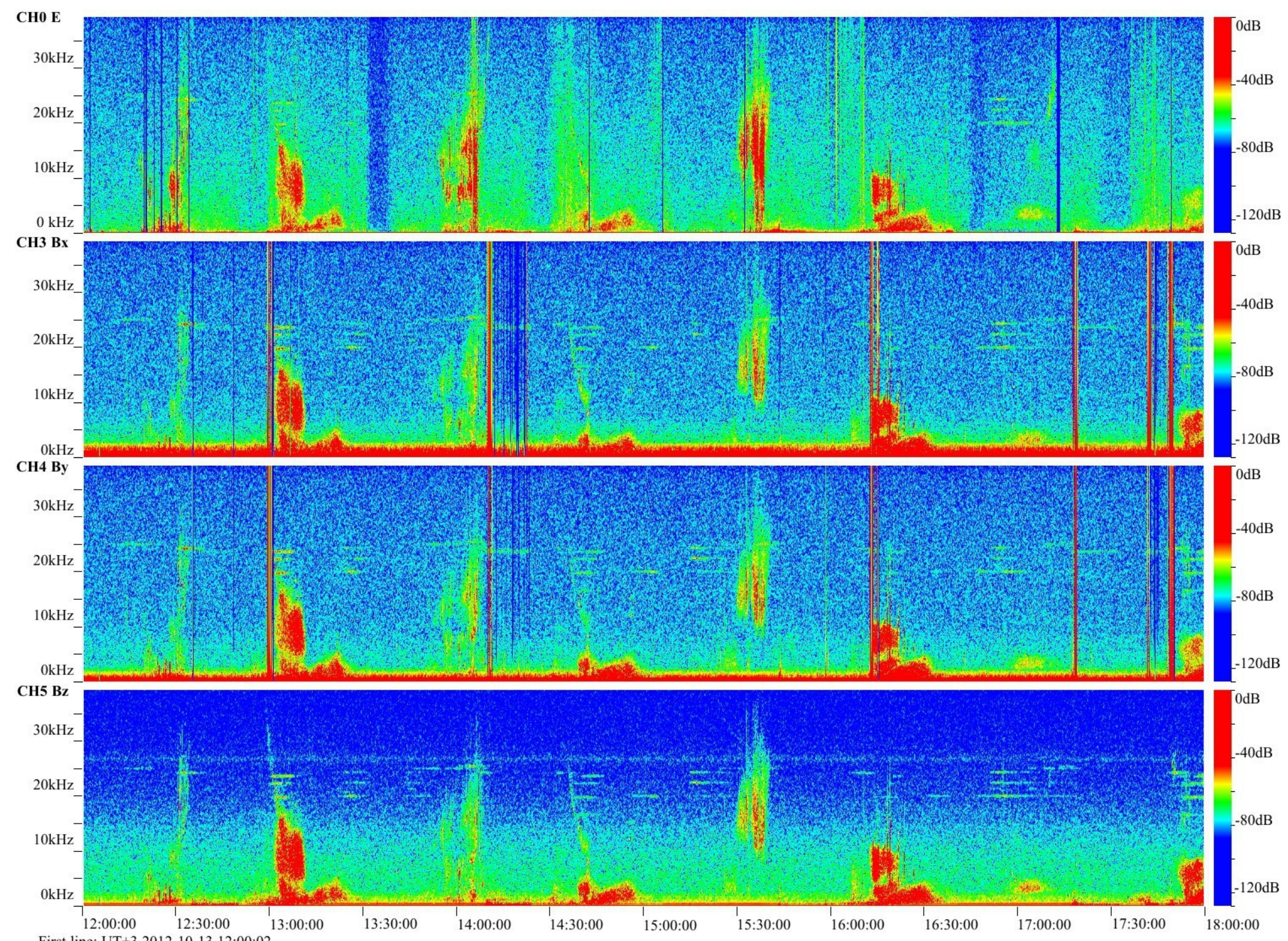

First line: UT+3 2012-10-13 12:00:02

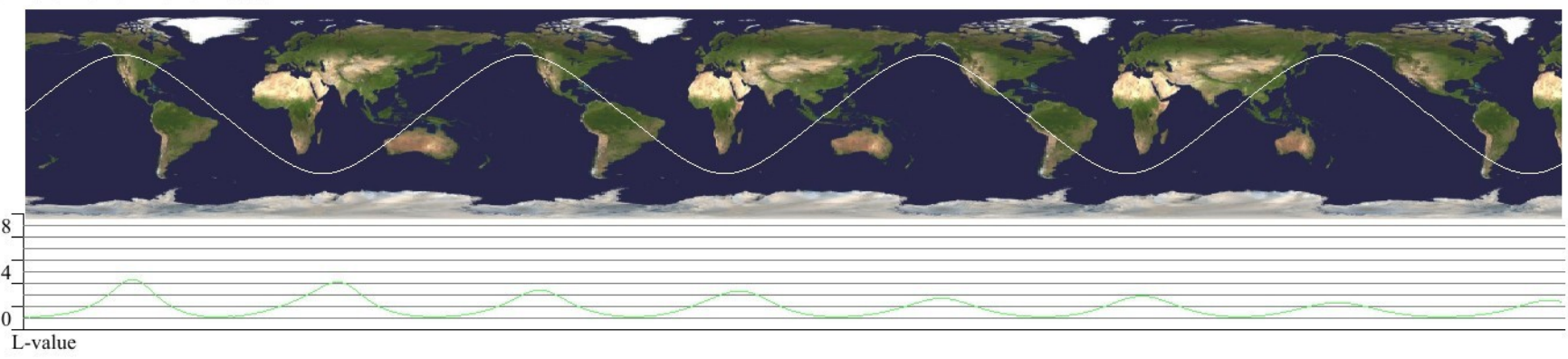

Figure 7b. Monitoring mode (1) SAS3 data recorded by the Chibis-M in $13^{\text {th }}$ October 2012. This record contains the second part and the attenuation of the geomagnetic storm. The beginning of the 6 hours long record is $U T+3=12.00 .00$.

Based on the results presented above it is possible to conclude that the SAS3 monitoring mode is and will be a good tool for Space Weather research and monitoring; and in the future it can be a basic tool to produce a satellite based (hoped) Space Weather Service System. 


\section{Examples of results in burst mode records}

In the following only a few examples will present from the scientifically interesting records measured by the SAS3 of the Chibis-M. (The detailed analysis of these examples is planned to publish in separate papers. Here we present only characteristic records with hopefully new indications.)

a) It is important to measure the detailed electromagnetic wave forms in the $>20$

\section{$\boldsymbol{k H z}$ VLF band:}

In most cases on board of satellites detailed wave-form measurements happened typically in the $\leq 20 \mathrm{kHz}$ ULF-VLF bands. The Chibis-M is one of the few satellite missions in which detailed signal shape recordings happened in the $>20 \sim 100 \mathrm{~Hz}$ to $\leq 40$ $\mathrm{kHz}$ band, i.e. above $20 \mathrm{kHz}$. These records confirm that in these higher frequencies interesting signals appeared in the Chibis-M records, which could result new scientific knowledge. In Fig. 8 strong fractional hop whistlers were recorded in the whole band up to $40 \mathrm{kHz}$. (In the figure caption $\varphi$ is the geographical latitude and $\lambda$ is the geographical longitude.) The main panel in the figure (top left) is the FFT dynamic spectrum of the recorded signal. The color scale of the FFT patterns is relative FFT amplitude in $\mathrm{dB}$ (right panel in the figure). The bottom panel is the recorded time function of the signal; in which the dark blue section is that part which is presented in the top left FFT panel. (This form is a consequence of the applied Matlab FFT software.)

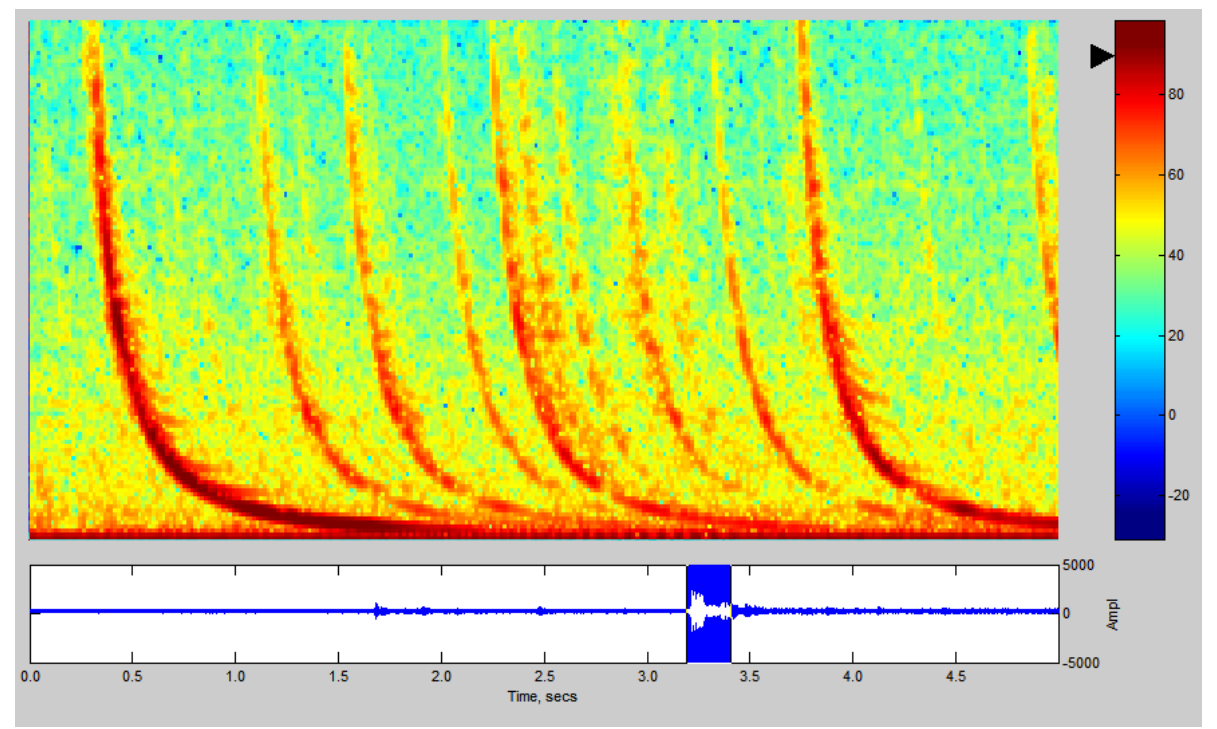

Figure 8. Strong fractional hop whistlers with Spiky Whistler (SpW) [Ferencz et al., $2007]$ character and with strong signal parts above $20 \mathrm{kHz}$; recorded by the Chibis-M satellite. ( $B_{z}$ channel; $5^{\text {th }}$ September 2012, 21.14.54UT; $\varphi=-20^{\circ}, \lambda=+27^{\circ}$.)

In the Fig. 9 strange shape, non-identified (!) signal series is presented in which above the whistler-like part of this complex signal group and above $20 \mathrm{kHz}$ interesting and perhaps important signal part appeared with diffuse character. In the signal formation 
the $>20 \mathrm{kHz}$ parts are important characteristic features. Therefore the identification and investigation of this phenomenon is possible only with such instruments which can record the incoming signals in the whole near to DC to $40 \mathrm{kHz}$ band. (Further investigation of these strange signal series is under way.) The main panel in the figure (top left) is the FFT dynamic spectrum of the recorded signal. The color scale of the FFT patterns is relative FFT amplitude in $\mathrm{dB}$ (right panel in the figure). The bottom panel is the recorded time function of the signal; in which the dark blue section is that part which is presented in the top left FFT panel.

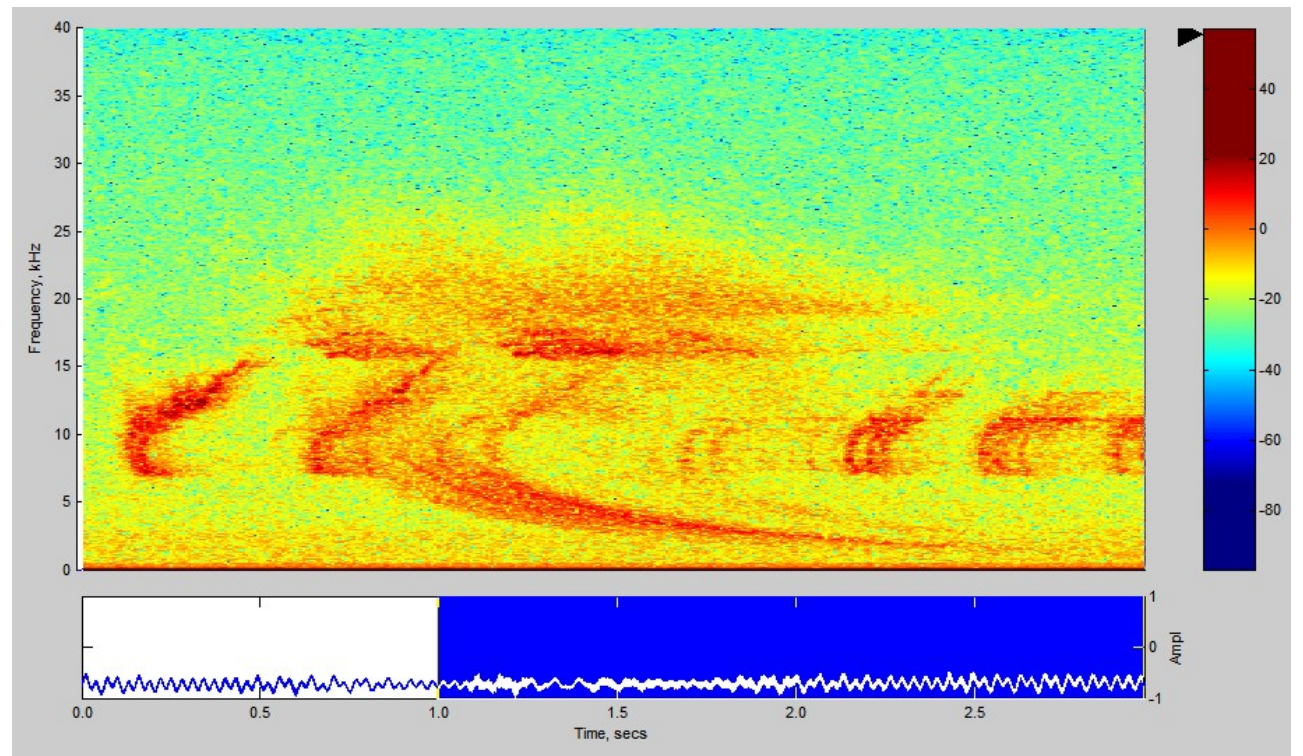

Figure 9. Signal series with strange signal shape, which was not identified earlier and has important parts above $20 \mathrm{kHz}$; recorded by the Chibis-M satellite. (E channel; $7^{\text {th }}$ June 2012, 02.17.01 UT; $\varphi=+50^{\circ}, \lambda=+25^{\circ}$.)

b) New, scientifically valuable data collected by the Chibis-M in the cases of some identified types of whistler signals:

- Spiky Whistlers: Earlier using the DEMETER records the nature and origin of the SpW signals [Ferencz et al., 2007]. SpW's were recorded systematically by the Chibis-M too (Fig. 9) and the appearance of these signals in the burst records confirms that the SpW's could be an effective tool in the monitoring of the dynamics of bottom boundary of the ionosphere, of the D region. (See more about the method in the [Ferencz et al., 2007].

- Whistlers propagating in ducted mode: By the application of the Compass-2 (with SAS2 instrument) burst mode recorded signals first time was possible to identify whistlers propagating in ducted, i.e. guided mode [Ferencz et al., 2009]. After an ULFVLF noise filtering of the signals recorded by the Chibis-M (SAS3) signals propagating in guided mode appeared too. (The noise filtering method will be published in details in another paper.) The specific character of the guided ultra wide band (UWB) signals is presented in Fig. 10 with a Compass-2 SAS2 record; and the noise filtered FFT pattern of a Chibis MWC record in Fig. 11. The color scale in the Figs. 10 and 11 is the relative FFT amplitude in $\mathrm{dB}$. - The scientific question generated by these records of the Chibis MWC 
measurements is that if these signals are really guided mode signals propagating in a waveguide filled with magnetized plasma than this wave-guide effect appeared in the ionosphere between the bottom boundary of the ionosphere and the satellite and not in the magnetosphere propagating e.g. along the geomagnetic field lines in a magnetospheric duct. How is it possible? But the recorded signal shape has really guided mode pattern. The characteristic pattern of the guided UWB signals propagating in a wave-guide filled with magnetized plasma is written in details in [Ferencz et al., 2009].

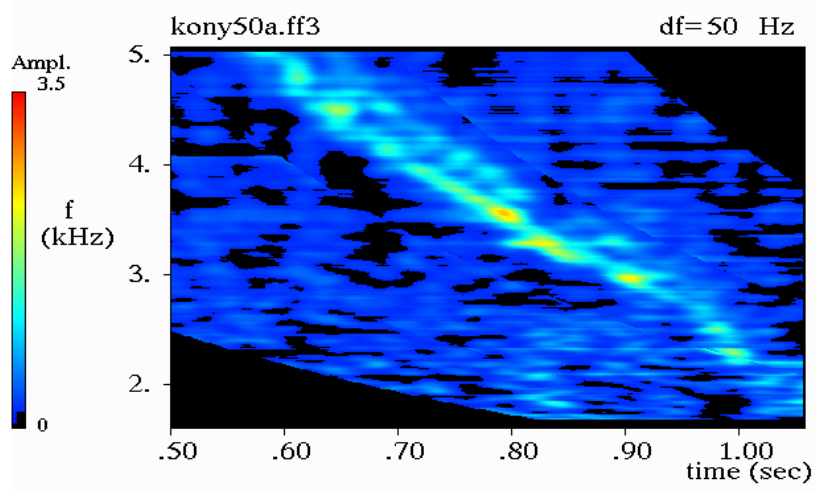

Figure 10. Matched filtered pattern of the lower part of a whistler-group propagating in higher-order guided mode with the characteristic decreasing end of the signal pattern without any asymptotic effect; recorded by Compass-2 satellite in $28^{\text {th }}$ February 2007 [Ferencz et al., 2009].

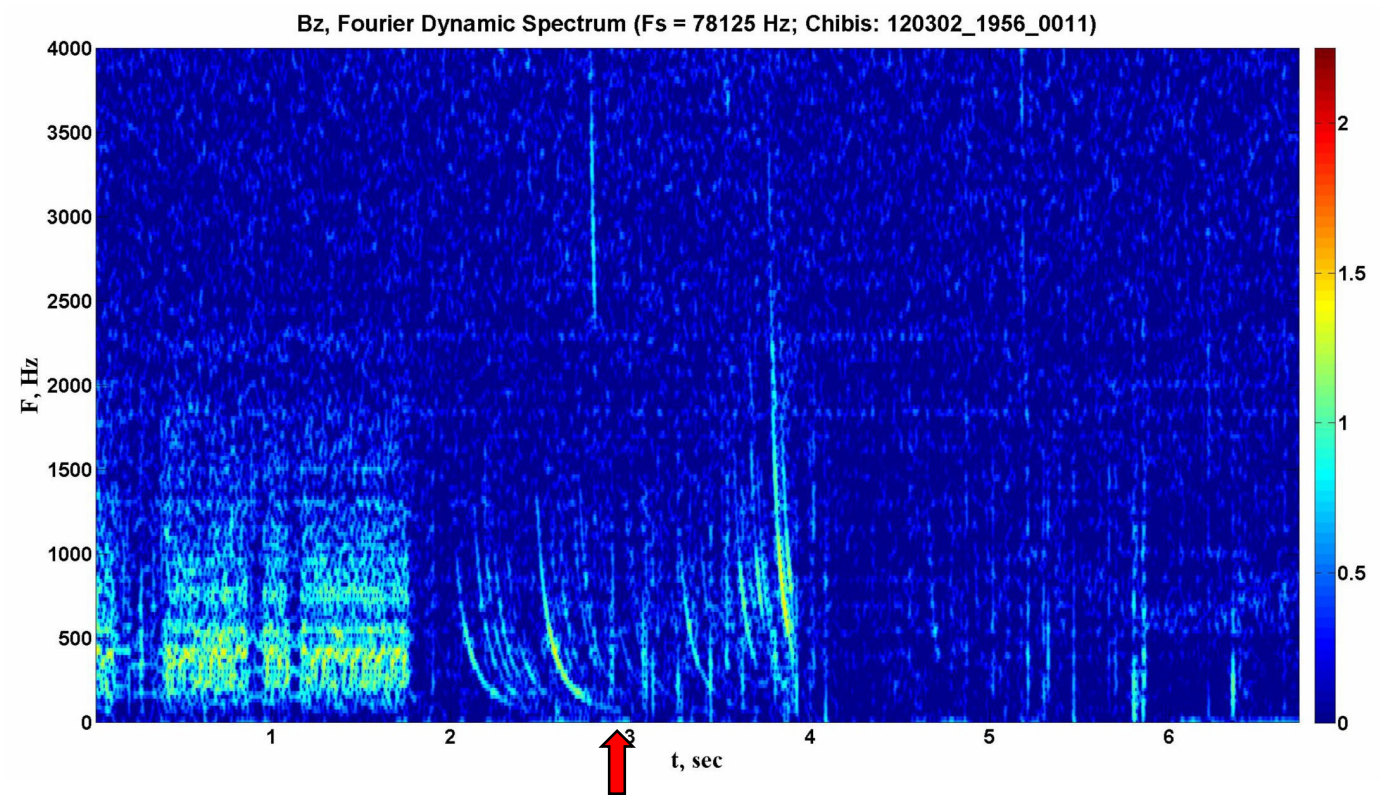

Figure 11. Fractional hop whistlers with guided mode like shape recorded by the Chibis $M W C$. The red arrow indicates the guided mode like end of a stronger fractional hop whistler in this Chibis MWC record. (B $B_{z}$ channel; $2^{\text {nd }}$ March 2012, 16.56.00 UT; $\varphi=+6^{\circ}$, $\lambda=-104^{\circ}$ ) 
- The signals crossing the ionosphere propagating from the troposphere to the satellite appeared in pairs having together trapezoid character [Steinbach, 2006] and it is known an UWB propagation interpretation of these signals. However, in the Chibis MWC records signal triplets appeared also adding new aspects to the investigation of the out-coupling of lightning energy from the troposphere to the ionosphere (Fig.12.). - The top panel of Fig. 12 is the FFT pattern of the signal recorded by the Chibis SAS3 instrument and the bottom panel is the time function of the recorded signal incoming to the SAS3 from the $B_{z}$ sensor (Fig. 1b). - In the FFT pattern we see two strong fractional hop whistlers ( $1^{\text {st }}$ traces). Measuring the time delay in $3.5 \mathrm{kHz}, 117 \mathrm{~ms}$ later from each $1^{\text {st }}$ trace we find two $2^{\text {nd }}$ traces with the same time differences each other as in the case of the $1^{\text {st }}$ traces. And in this case (measuring the time delay in $5.6 \mathrm{kHz}$ ) $312 \mathrm{~ms}$ later from each $1^{\text {st }}$ traces two $3^{\text {rd }}$ traces appear also with the same time differences each other as in the case of the $1^{\text {st }}$ traces. This is the illustration of the result derived with detailed UWB propagation model that the three components of these signal triplets (!) have the same source signals. Naturally, the source signals of the two whistler-triplets are different; however, the propagation configuration is the same.

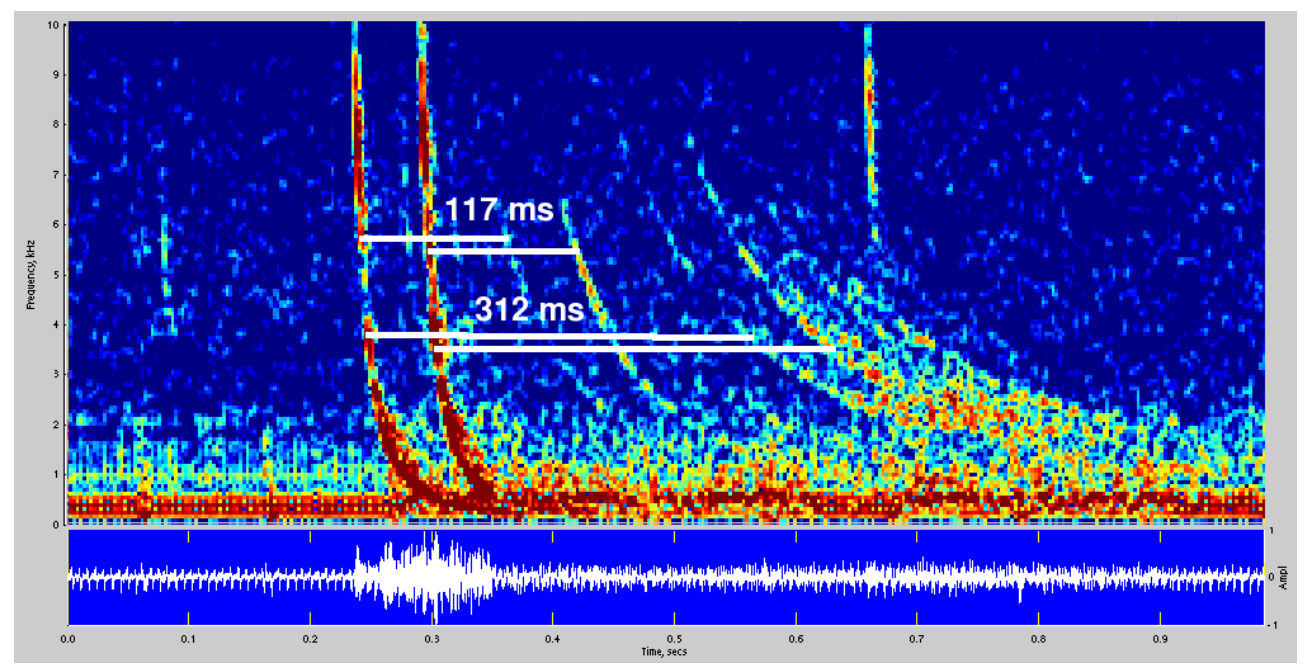

Figure 12. Fractional hop whistler triplets who appear systematically in the Chibis MWC records and the members of a triplet have the same source signal. ( $B_{z}$ channel; $18^{\text {th }}$ September 2012, $21.50 .31 U T ; \varphi=+23^{\circ}, \lambda=-93^{\circ}$.) Time delays are measured in 3.5 and $5.6 \mathrm{kHz}$ frequencies. This phenomenon is identified first time in the Chibis MWC records.

- Ion whistlers with unusual character: The ion whistlers are deeply investigated signals. However, in the Chibis MWC records we found record of ion whistlers having different upper asymptotic frequency which were recorded in the same place and in the same time and appeared simultaneously (Fig. 13). Because these signals appeared in the same location, the local plasma parameters are the same. The values of the upper asymptotes of these ion whistler series in this record are $\leq 520 \mathrm{~Hz}$ and $\geq 435 \mathrm{~Hz}$. These values exclude that the cause of this phenomenon could be the effect of the heavier ions beside the protons. Because the traversed medium is the same it is possible that the cause of this phenomenon is the direction of the propagation comparing to the geomagnetic field strength, i.e. trapezoid whistler pairs (see above) propagate through the ionosphere and the accompanying ion whistlers could have these different upper asymptotes. (See 
more in [Ferencz et al., 2001].) It is necessary to continue the investigation of this phenomenon theoretically and experimentally too.

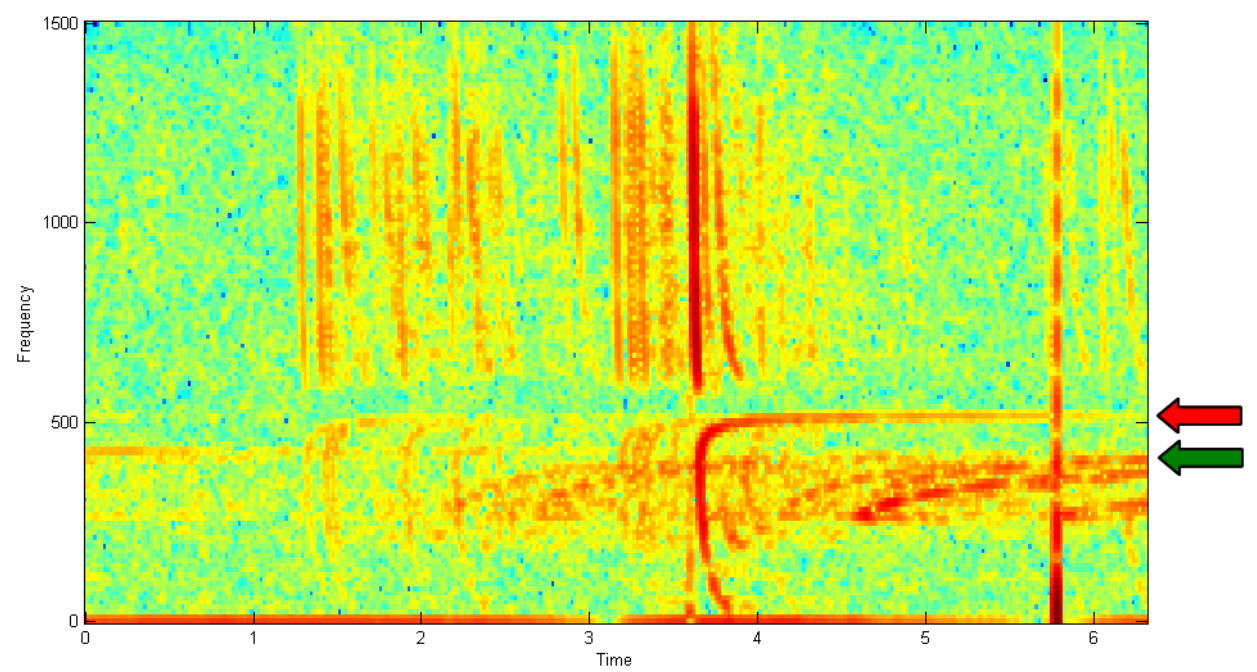

Figure 13. Ion whistler series in a Chibis MWC record in which ion whistlers appear with two different upper asymptotes simultaneously in the same time. See the red and green arrows. (E channel; $19^{\text {th }}$ August 2012, 21.53.46UT; $\varphi=-1^{\circ}, \lambda=+99^{\circ}$ )

- Swallow-Tailed Whistlers (STW): These unusual VLF signatures (Fig. 14) were identified in the DEMETER records [Ferencz et al., 2010]. The origin of these signal structures is still unknown. After the DEMETER mission we know the existence of these signals, but the generation mechanism and the generation region were unknown. In the Chibis MWC SAS3 records STW features appeared also. But these STW signals have only the same dispersion as the normal fractional hop signals (Fig. 15) which propagate in the shortest way to the satellite from the Earth surface - ionosphere waveguide. Therefore it is probable, that the generation region of these types of signals is in the ionosphere below the Chibis-M orbit height. We must exclude from the possible generation regions the magnetosphere, the plasmasphere; the lower ionosphere remained only as a possible generation region. Hopefully, in the following the Chibis-M (and other planned ionosphere satellites) will record such kind of signals. The generation mechanism is still unknown, however, with this Chibis MWC record we are closer to understand the origin of these STW signals. 


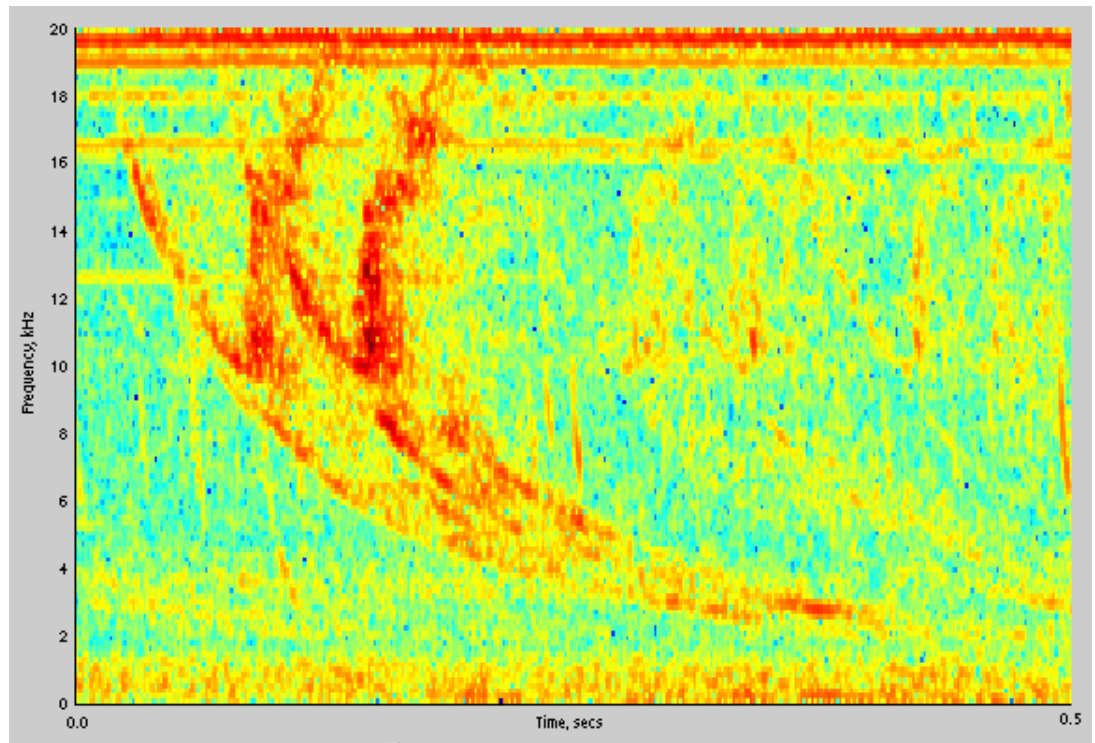

Figure 14. Normal STW signals with simultaneous appearing fractional hop whistlers in a Demeter satellite record. (16 $6^{\text {th }}$ October 2004, 2055:09.0 UT.) [Ferencz et al., 2010]

The main panel (top left) in the figure 15 is the FFT dynamic spectrum of the recorded signal. The color scale of the FFT patterns is relative FFT amplitude in $\mathrm{dB}$ (right panel in the figure). The bottom panel is the recorded time function of the signal; in which the dark blue section is that part which is presented in the top left FFT panel.

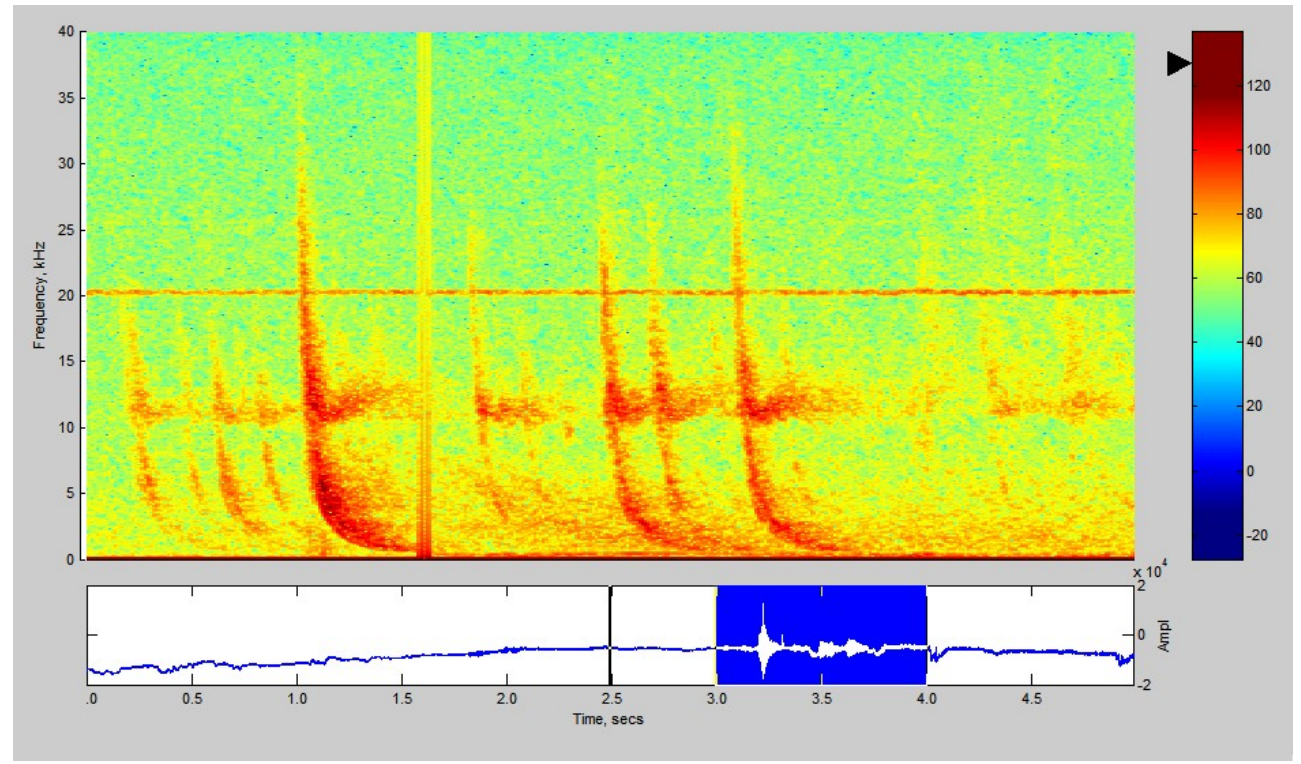

Figure 15. STW signal structure on fractional hop whistlers recorded on board of ChibisM micro-satellite. (E channel; $21^{\text {st }}$ July 2012, 20.23.35 UT; $\varphi=+1^{\circ}, \lambda=+110^{\circ}$ )

It is possible to say that the application of this SAS3 waveform recording mode with these types of sensors is an important and effective tool in wave propagation and high atmosphere research. 


\section{First results of the event counting mode}

In this mode the MWC SAS3 instrument produces data which are directly applicable for statistical investigations of the ionosphere and Space Weather phenomena. The transient activity distribution along the satellite orbit is a good tool in the investigation of the out-coupling processes of the electromagnetic (lightning) energy from the troposphere into the higher regions, the depending of these processes on the geographic and/or geomagnetic positions and the changing of this activity in the time with the regular processes (local time, seasonal dependence, etc.) and with the solar effects (Space Weather). In Fig. 16 an event detector record is presented as an example of the systematic geographical dependence of the electromagnetic transient activity at the satellite, which is different of the lightning geographical distribution in the troposphere. In this mode it is possible to define for the SAS3 the character of the interesting phenomena, i.e. this is a transient which is very short in time (e.g. fractional hop whistlers), but appearing in a large sequence along the frequency axis, or a transient longer in time (e.g. normal whistlers), or transient with multi peaks, etc. The time window of the counting of the selected type of transients was defined as 1 min. Because the main goal of the Chibis-M mission is the search of the lightning activity, the thunderstorm activity ("Groza") and the lightning generated signals coming below the satellite propagate in the shortest way from the lightning to the satellite, it was selected in the SAS3 in these first measurements to count the transients which are very short in time.

Event counts
Waveform saved

$$
20
$$

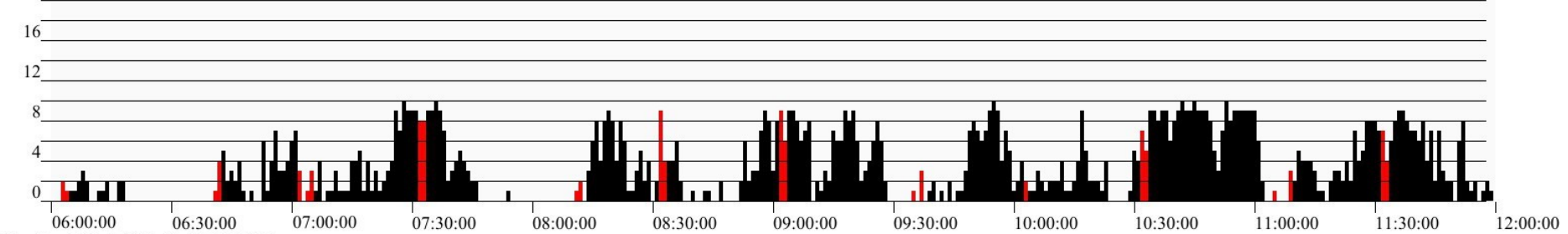

First line: UT+3 2012-11-11 06:01:02
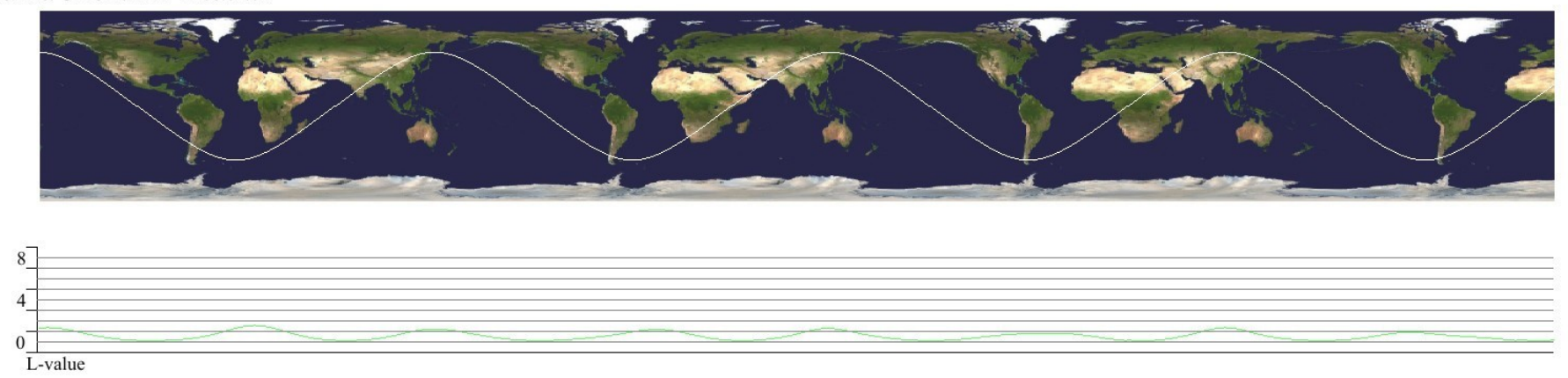

Figure 16. Electromagnetic event (transient) counting number distribution (top) along the Chibis-M orbit (middle) and with different L-values (bottom) recorded by the Chibis$M$; the 6 hours long recording started in 11.11.2012,UT+3=06.00.00. 
In the Fig. 16 top panel the red columns indicate that simultaneously with this counting the detailed waveform of minimum one event was stored (recorded) too. In the case of the black columns the SAS3 stored only the number of the selected events counted during the 1 min. time window. In the middle panel the white sinus-like line is the sub-satellite line of the Chibis-M satellite on the map of the Earth surface and the bottom panel contains the simultaneous L-values of the satellite position (light green line).

We can say that this operation mode is a very good tool for the continuous monitoring and dynamic mapping of the transient activity at the satellite level which is important for the Space Weather and geophysical research. E.g. in the systematic changing of the count number along the satellite orbit indicates that around the geomagnetic equatorial region only a small number of the lightning generated signals can propagate through the ionosphere to the satellite (as fractional hop whistlers), however, out of the ionosphere region bounded by the electron density maximums of the ionosphere from north and south of the geomagnetic equator the lightning generated UWB VLF signals can penetrate easy the ionosphere. (See [Steinbach, 2006] too.) The changing in this phenomena in time and geographically is an interesting theme in the Space Weather research, and naturally it mirrors the changing in the lightning activity too. This means that the continuous running of this kind of event counting on board of Chibis-type satellites is important for future research. The applicability of these records in the seismic research is still an open question.

\section{Conclusions}

The new micro-satellite construction and technology confirmed by the good work of Chibis-M in orbit.

The Chibis-M electromagnetic wave complex (the MWC and in this the SAS3 equipment) is effective in ionosphere and Space Weather research and it is a good tool in the (near) future to start the operative monitoring of the ionosphere for a Space Weather warning system. This measuring system is useful in the investigations of the Earths and planetary electromagnetic environment. This system is also hopeful in the search of earthquake precursors.

In this application the measurements having capacity to produce real wave-form recording and signal investigation possibilities in the ULF to $\geq 40 \mathrm{kHz}$ band are necessary because in the $>20 \mathrm{kHz}$ band important indicators were found during intense geomagnetic activity and characteristic signals appeared in a lot of detailed electromagnetic wave-form records.

All three operation modes work well, and to realize an effective research and monitoring of the electromagnetic environment of the Earth the simultaneous application of these modes is effective.

Acknowledgement: We thank the friendship and partnership of a hard working and brave man, eng. László Bodnár, who died before the end of the first active year of the Chibis-M. He was an engine and a valuable source of the ideas of these measurements, and he planned and produced the SAS3-CH instrument. We remember for him. 
These works were supported by the SSAU grant \# 1-05/08; the RFBR grant's 0905-13587-ofi, 10-05-93107-GDRI; and by the Hungarian government space-oriented support.

\section{References:}

Akhoondzadeh M., Parrot M. and Saradjian M.R. (2010): Electron and ion density variations before strong earthquakes $(\mathrm{M}>6.0)$ using DEMETER and GPS data. Natural Hazards and Earth System Science, 10, 7-18

Bobrinsky N. (2009): The European SSA preparatory programme. $5^{\text {th }}$ meeting of the PECS committee, ESRIN, Italy

Dudkin F., Korepanov V., Lizunov G. (2009): Experiment VARIANT - first results from Wave Probe instrument. Adv. Space Res., 43 (12), 1904-1909

Ferencz Cs., Ferencz O.E., Hamar D. and Lichtenberger J. (2001): Whistler phenomena; Short impulse propagation. (Sec. 2.4) Kluwer Academic Publ., Dordrecht.

Ferencz O.E., Ferencz Cs., Steinbach P., Lichtenberger J., Hamar D., Parrot M., Lefeuvre F. and Berthelier J.-J. (2007): The effect of subionospheric propagation on whistlers recorded by DEMETER satellite - observation and modelling. Ann. Geophys., 25, 1103-1112

Ferencz O.E., Bodnár L., Ferencz cs., Hamar D., Lichtenberger J., Steinbach P., Korepanov V., Mikhaylova G., Mikhaylov Y. and Kuznetsov V. (2009): Ducted whistlers propagating in higher-order guided mode and recorded on board of Compass-2 satellite by advanced Signal Analyzer and Sampler 2. J. Geophys. Res., 114, A03213, doi:10.1029/2008JA013542

Ferencz Cs., Lichtenberger J., Hamar D., Ferencz O.E., Steinbach P., Székely B., Parrot M., Lefeuvre F., Berthelier J.-J. and Clilverd M. (2010): An unusual VLF signature structure recorded by the DEMETER satellite. J. Geophys. Res., 115, A02210, doi:10.1029/20099JA014636

Gurnett D.A., Zarka P., Manning R., Kurth W.S., Hospodarsky G.B., Averkamp T.F., Kaiser M.L. and Farrell W.M. (2001): Non-detection at Venus of high-frequency radio signals characteristic of terrestrial lightning. Nature, 409, 313-315

Klimov, S.I., V.G.Rodin, L.M.Zelenyi, V.N.Angarov. Development of the method of the creation of micro-satellite $(\sim 50 \mathrm{~kg})$ platforms for the fundamental and applied research of the Earth and near-earth outer space. Small Satellites for Earth Observation. Digest of the $6^{\text {th }}$ International Symposium of the International Academy of Astronautics, Berlin, April 23-26, 2007. Edited by Rainer Sandau, Hans-Peter Roeser, Arnoldo Valenzuela. Wissenschaft und Technik Verlag, Berlin. p. 311-314.

Klimov S.I., Angarov V.N., Nazarov V.N., Batanov O.B. and Antonenko E.A. editors (2009a): Missija Chibis-M. (in Russian), IKI-RAN, Moscow, ISSN2075-6836

Klimov, S.I., Korepanov V.E., D.I. Novikov, Ferencz Cs., Lichtenberger J., Marusenkov A. and Bodnár L. (2009b): Study of electromagnetic parameters of space weather. Micro-satellite "CHIBIS- M". Small Satellites for Earth Observation". Digest of the $7^{\text {th }}$ International Symposium of the International Academy of Astronautics (IAA), Berlin, May 4-8, 2009. Editors: Rainer Sandau, Hans-Peter Roeser, Arnoldo Valenzuela. Wissenschaft und Technik Verlag, Berlin, p. 65-68. 
Ksanfomaliti L.V. (1979): Molnii v oblatsnom sloe Veneri. (in Russian) Kosmich. Issl., XVII, 747-762

Korepanov V. (2003): The modern trends in space electromagnetic instrumentation. Adv. Space Res., 32, 401-406

Märcz F. and Harrison R.G. (2003): Long-term changes in atmospheric electrical parameters observed at Nagycenk (Hungary) and the UK observatories at Eskdalemuir and Kew. Ann. Geophys., 21, 2193-2200

Molchanov O., Rozhnoi A., Solovieva M., Akentieva O., Berthelier J.-J., Parrot M., Lefeuvre F., Biagi P.F., Castellana L. and Hayakawa M. (2006): Global diagnostics of the ionospheric perturbations related to the seismic activity using the VLF radio signals collected on the DEMETER satellite. Natural Hazards and Earth System Science, 6, 745753

Parrot M., Berthelier J.-J., Lebreton J.P., Sauvaud J.A., Santolik O. and Blecki J. (2006): Examples of unusual ionospheric observations made by the DEMETER satellite over seismic regions. Physics and Chemistry of the Earth, 31, 486-495

Russell C.T., Zhang T.L., Delva M., Magnes W., Strangeway R.J. and Wei H.Y. (2007): Lightning on Venus inferred from whistler-mode waves in the ionosphere.

Nature, 450, 661-662

Sátori G., Mushtak V. and Williams E.R. (2009): Schumann resonance signatures of global lightning activity; in "Lightning: Principles, Instruments and Applications, Review of Modern Lightning Research", ed. by Betz H.D. et al., Springer, 347-386

Smith A.J., Horne R.B. and Meredith N.P. (2008): ELF/VLF waves of magnetospheric and terrestrial origin: 16 years of continuous observations in Antarctica; 3rd VERSIM Workshop, Tihany, 15-20 September 2008, ISBN 978-963-284-017-8

Steinbach P. (2006): Oblique whistler propagation in the ionosphere - results of the first application of a full-wave propagation model on DEMETER burst recordings. $2^{\text {nd }}$ VERSIM Workshop 2006, SGO, Sodankylä, Finland, Report No. 56.

Taylor W.W.L., Scarf F.L. and Brace L.H. (1979): Evidence for lightning on Venus; Nature, 279, 614-616

Zeren Zhi-Ma, Shen Xu-Hui, Cao Jin-Bin, Zhang Xue-Min, Huang Jian-Ping, Liu Jing, Ouyang Xin-Yan, Zhao Shu-Fan (2012): Statistical analysis of ELF/VLF magnetic field disturbances before major earthquakes. (in Chinese) Chinese J.Geophys., 55(11), 3699-3708, doi:10.6038/j.issn.0001-5733.2012.11.017. 